\title{
Neuromonitoring to avoid euthanasia in a quadriplegic patient
}

\author{
Geert Vermeersch ${ }^{1}$ \\ ${ }^{1}$ Spinal surgery department, Algemeen Ziekenhuis Jan Portaels, Vilvoorde, Belgium \\ geert. vermeerscheazjanportaels.be
}

\begin{abstract}
Background: Under very limited circumstances euthanasia can be performed in Belgium since 2002 (Verwilghen, 2012). If a patient has medical condition with no hope on improvement, with physical and/or psychological suffering, he can ask for terminating his life. The written demand is on voluntary bases, well considered, repeated and was not induced due to external pressure from other people. Neuromonitoring has been used in spine surgery during the last four decades. (Lall, et al., 2012) (Gonzales, Jeyanandarajan, Hansen, Zada, \& Hsieh, 2009) With the development of new modalities, new applications were introduced in spine surgery in order to avoid neurological damage during surgical procedures.

Method: A patient with a partial recovered ASIA A C7 quadriplegia suffering from wounds caused by his spinal instrumentation had intraoperative neuromonitoring. In case he became dependent for his personal care, he wanted to have euthanasia executed on him.

Conclusion: So far there is no literature on the use of neuromonitoring to avoid euthanasia in cases where spinal surgery is needed, but surgery has an inherent risk of causing damage to nerval structures, which can cause loss of recovered nerve function after spinal cord injury. This potential loss of independence was an unbearable physical and psychological suffering the patient would not want to go through again. By using neuromonitoring, the key muscles were observed during the surgery. No neurological events were seen during the prodecure. He had some general weakness after the surgery but kept his autonomy, so no euthanasia was needed.
\end{abstract}




\section{Introduction}

Neuromonitoring has a lot of practical indications in preventing neurological damage from happening during surgery. The case here described, is an atypical case in which neuromonitoring was used to avoid neurological damage in a partialy recovered quadriplegic patient who had requested euthanasia, should the surgery cause a return to a quadriplegic state.

\section{Case history}

A 55 year old man presents himself to outpatient clinic 2 years after an accident with a very specific question. He suffered a spinal cord injury (ASIA A C7 after fracture-dislocation of C7-T1) for which he had undergone a posterior cervicothoracic screw fixation (Figure 1). During his rehabilitation, he recovered full use of his upper limbs and became an active wheelchair bound patient (level T2). He wants his hardware to be removed, as well as the very prominent spinous processi at the cervicothoracic junction because he feels the hardware and the processi are constantly pushing against the skin. There have not been any wounds yet at this level since the key surgery, but he has become afraid to develop pressure sores at this region. When asking for this surgery, the patient has a very specific request. If, during the surgery, he would suffer loss of function of his arms and/or hands; he wanted active euthanasia to be performed on him. He expresses unbearable psychological suffering if he would become more dependent due to his surgery.

\section{Legal Situation}

As euthanasia is legal in Belgium since May 28 2002 under very specific circumstances as described by the Belgium law (Verwilghen, 2012), this request is treated as legitimate question. The conditions that need to be fulfilled for euthanasia are:

- The written demand is on voluntary bases, well considered, repeated and was not induced due to external pressure from other people;

- The patient has a medical condition without any hope on improvement

- The physical and/or psychological suffering is constant and unbearable, there are no solutions to alleviate the suffering

- The medical condition is caused by an incurable and burdensome disease and/or an accident

- The patient has to be over 18 years old and to be able to judge for himself

- In case of a minor (aged under 18), but already able to judge for himself. The decision on the ability of the minor to judge on him-/herself is made by a psychologist or children's psychiatrist. 


\section{Method}

General and patient specific risk factors were assessed. One risk factor was considered to be important for further investigation: intraoperative neurological damage can be caused by hypotension during the surgery. Because of repetitive fluctuations of blood pressure resulting in hypotension since his accident, a cardiologist was consulted and he was prescribed Fludrocortison $100 \mu \mathrm{g}$ once a day to get his blood pressure higher and more stable.

A CT-scan (Figure 1)was requested to evaluate the consolidation of the fracture. The initial surgical team was contacted in order to have the correct set of tools available during the surgery.

All the risks and benefits of the surgery were discussed and noted down. The patient was still willing to have the surgery done and repeated his request to have euthanasia performed in case of loss of function of his upper limbs. He consented on having neuromonitoring performed on him.

During surgery, the patient was installed in a supine position and received Total IntraVenous Anesthesia (TIVA). A biting block was inserted to prevent tongue-biting injuries during the evoked potentials. Once under TIVA, neuromonitoring was installed on the head and arms for Upper-Limb monitoring. SomatoSensory Evoked Potentials (SSEP) (Lall, et al., 2012) were performed on the median nerve of both hands. Motor Evoked Potentials (MEP): the orbicularis oris muscle was selected as reference muscle, while the key muscles for follow-up during the surgery were deltoid muscle (C5), biceps (C6), triceps (C7) and intrinsic hand muscles (C8-T1) (Gonzales, Jeyanandarajan, Hansen, Zada, $\&$ Hsieh, 2009). Baseline values were acquired in supine position. With all electrodes in place, patient was turned with the Jackson table to prone position. As soon as the patient was installed, measurements were repeated. There were no signs of changes in the SSEP and the MEP.

The previous scar was prepped and draped. When all the material was ready to be taken out, another round of SSEP and MEP was run without any changes. After removing of all the material and having trimmed down the prominent spinous processi, monitoring was performed and still no changes had occurred. After closing and turning him back to a supine position, a final assessment was made, with all the key muscles still intact (the observed changes were not significant) (Nash, Lorig, Schatzinger, \& Brown, 1977) (Schwartz, Auerbach, Dormans, Flynn, \& Andrew, 2007)(Figure 2).

After surgery, the patient stayed in hospital for one week. Initially, he had anaesthesia induced general weakness which recovered. After a week and full healing of the wound, he felt strong enough to return to his own place.

\section{Conclusion}

Neuromonitoring has made spine surgery safer and is used in a lot of indications. A literature research has not revealed publications on neuromonitoring to avoid euthanasia. As euthanasia is only allowed in specific countries under very specific circumstances, there will not be a lot of experience in this field. As this patient had a repeated request for euthanasia in case of loss of function, the neuromonitoring helped to prevent nerve damage during the surgery by both surgical trauma and hypotension.

The loss of independence in a uncurable situation, causing physical and psychlogical suffering. If he had suffered loss of function from repeated injury to the spinal cord, he would have been able to ask for euthanasia. 


\section{Figures}
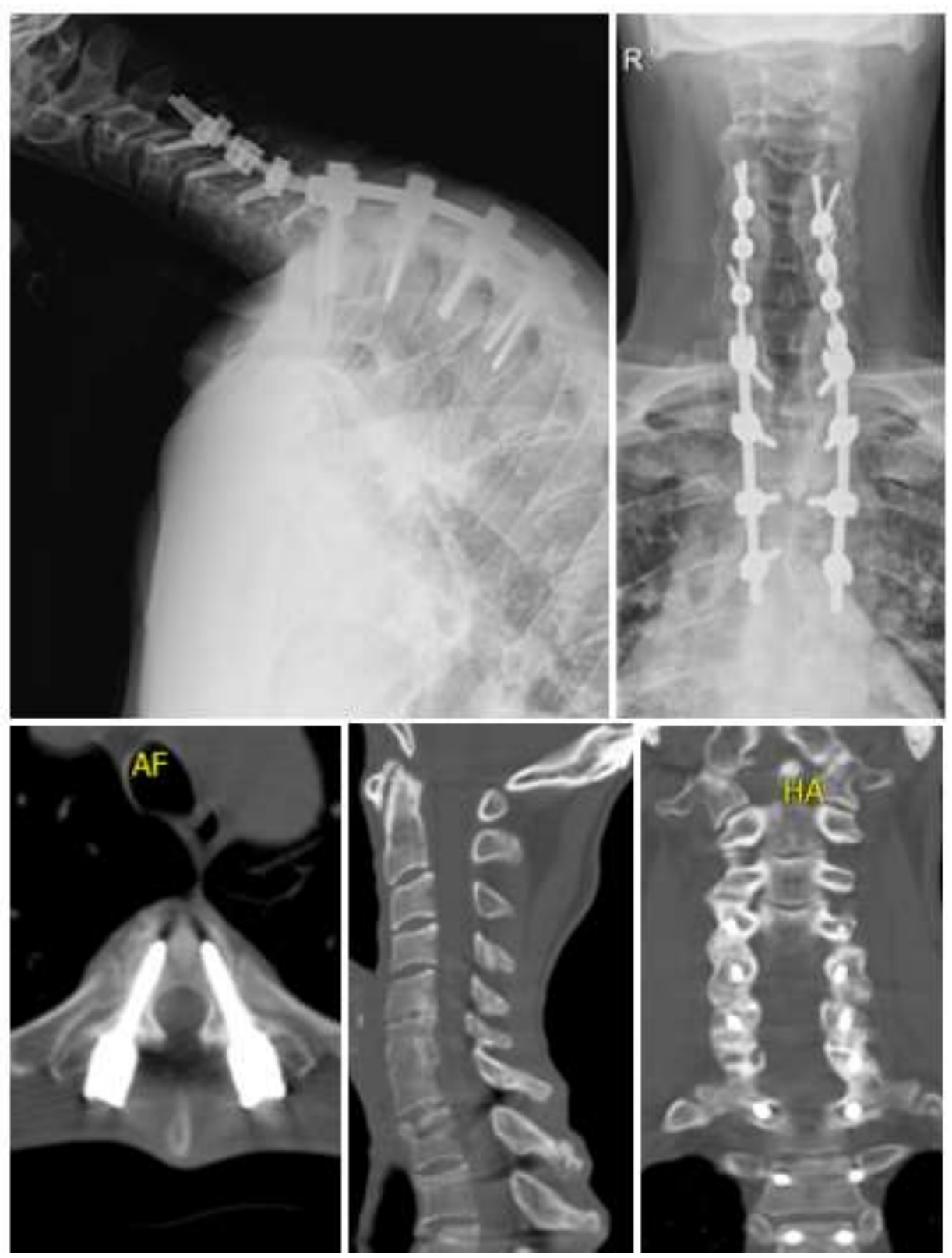

Figure 1: preoperative plain X-ray and CT scan showing material from C4 to T4, with prominent hardware and spinous processes pushing on the skin. 


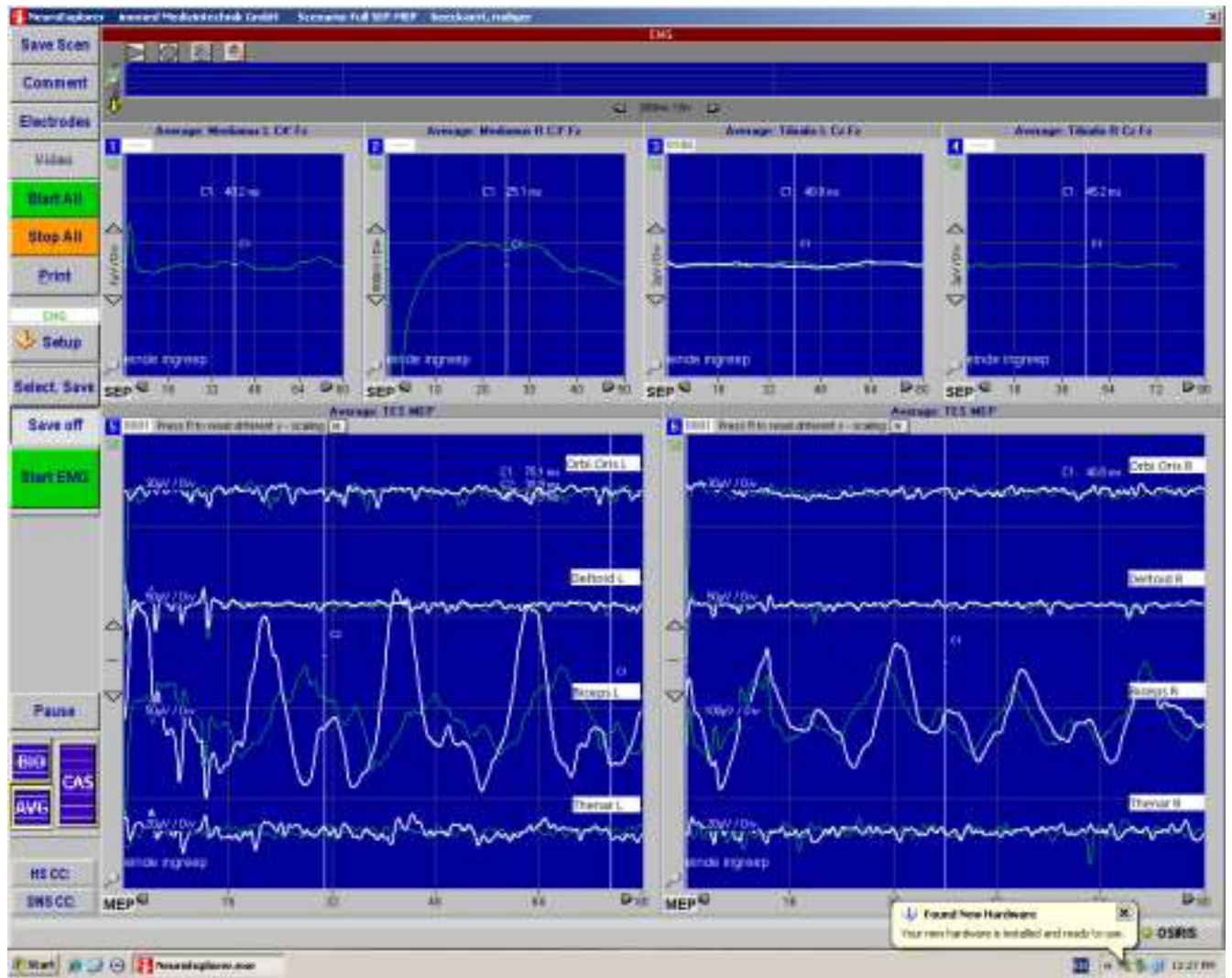

Figure 2: screenshot at the end of the procedure with baseline and at the end of surgery SSEP of median nerve and MEP of orbicularis oris, deltoid, biceps and hand muscle 


\section{References}

Gonzales, A. A., Jeyanandarajan, D., Hansen, C., Zada, G., \& Hsieh, P. C. (2009, Oct). Intraoperative neurophysiological monitoring during spine surgery: a review. Neurosurg Focus, 27(4). doi:https://doi.org/10.3171/2009.8.FOCUS09150

Lall, R. R., Lall, R. R., Hauptman, G., Munoz, C., Cybulski, G. R., \& Koski, T. (2012, Nov). Intraoperative neurophysiological monitoring in spine surgery: indications, efficacy, and role of the preoperative checklist. Neurosurg Focus, 33(5). doi:https://doi.org/10.3171/2012.9.FOCUS12235

Nash, C. L., Lorig, R. A., Schatzinger, L. A., \& Brown, R. H. (1977, Jul-Aug). Spinal cord monitoring during operatieve treatment of the spine. Clin Orthop Relat Res(126), 100-5.

Schwartz, D. M., Auerbach, J. D., Dormans, J. P., Flynn, J., \& Andrew, B. J. (2007, Nov). Neurophysiological detection of impending spinal cord injury during scoliosis surgery. $J$ Bone Joint Surg Am, 89(11), 2440-9. doi:10.2106/JBJS.F.01476

Verwilghen, M. (2012). Belgian Federal Law Website [Internet]: Wet betreffende de euthanasie. Retrieved from http://www.ejustice.just.fgov.be/eli/wet/2002/05/28/2002009590/justel 